\title{
The well pattern optimization of FuYang reservoir of Gaotaizi oilfield
}

\author{
Yu Guan
}

No.5 Oil-Extraction of Daqing Oilfield Company Ltd; Daqing 163513; China

Keywords: Rectangular well pattern; well spacing; well distance

\begin{abstract}
For low permeability reservoirs, the reasonable well pattern forms mainly depends on crack groups and bearing, Wells and well spacing depends mainly on fracture and the in situ stress field caused by seepage anisotropy, and the crack, the permeability ratio of the matrix;From the geologic features of low permeability reservoirs, in not equidistant well pattern development is an inevitable trend.Toward the 503 block of reservoir numerical simulation study results show that the rectangular way linear water flooding development effect is best, all kinds of well pattern and order of: rectangular linear injection pattern, method, square at 7 o 'clock pattern five points, square pattern against nine points.It is considered that the rectangular well pattern in the single well production, oil production rate and recovery degree, the water breakthrough time proof is better than other pattern, is currently the development effect of low permeability oilfield, the optimal solution. Using rectangular well pattern development can widen spacing, narrow row spacing, reduce the start-up pressure gradient, set up effective drive system, a low permeability reservoir is effective form of development pattern.
\end{abstract}

\section{Reasonable well pattern forms}

For low permeability reservoirs, the reasonable well pattern forms mainly depends on crack groups and bearing, Wells and well spacing depends mainly on fracture and the in situ stress field caused by seepage anisotropy, and the crack, the permeability ratio of the matrix;From the geologic features of low permeability reservoirs, in not equidistant well pattern development is an inevitable trend.Reservoir numerical simulation research results show that the rectangular way linear water flooding development effect is best, all kinds of well pattern and order of: rectangular linear injection pattern, method, square pattern at seven o 'clock five points, square pattern against nine points.It is considered that the rectangular well pattern in the single well production, oil production rate and recovery degree, the water breakthrough time proof is better than other pattern, is currently the development effect of low permeability oilfield, the optimal solution.

Using rectangular well pattern development can widen spacing, narrow row spacing, reduce the start-up pressure gradient, set up effective drive system, a low permeability reservoir is effective form of development pattern.

\section{Well drainage direction}

Songliao basin of daqing periphery stress research results show that the fu Yang bearing reservoir fracture system and the main bearing stress field is given priority to with east-west, high counter oilfield logging data show that fu Yang reservoir cracks in nearly east-west direction.

Tab2-1 Peripheral oil fields of fracture system, in-situ stress orientation and development dynamic statistics

\begin{tabular}{|c|c|c|c|c|c|}
\hline \multirow{2}{*}{ Oil field } & \multicolumn{2}{|c|}{ natural crack system } & \multicolumn{2}{c|}{ Artificial crack system } & \multirow{2}{*}{ Water orientatio } \\
\cline { 2 - 5 } & orientation & $\begin{array}{c}\text { density } \\
\text { (strip/m) }\end{array}$ & the main bearing stress & $\begin{array}{c}\text { Crack } \\
\text { orientation }\end{array}$ & NE \\
\hline Chaoyangditch & Near NE85 & 0.046 & $N E 74^{\circ} \sim \mathrm{SE96^{ \circ }}$ & NE85 & $\mathrm{NE}$ \\
\hline Yushulin & $N N E$ & 0.012 & $N E 85^{\circ} \sim N E 95^{\circ}$ & $\mathrm{NE}$ & $\mathrm{NE}$ \\
\hline Toutai & $N E 60^{\circ} 、 E 120^{\circ}$ & 0.057 & $N E 100^{\circ}$ & $\mathrm{NE}$ & $\mathrm{NE}$ \\
\hline
\end{tabular}

Extra low permeability reservoirs of artificial and natural cracks, common caused the reservoir 
plane heterogeneity, natural fracture due to under the condition of the formation is closed, its permeability is low, and artificial support fracture permeability can reach several darcy, on the ability of reservoir seepage control effect of artificial fracture, mainly as a result, low permeability reservoir configuration and optimization of well pattern is mainly artificial fracturing well pattern configuration and optimization.

Well drainage direction optimization: reservoir heterogeneity, well array requirements and the fracture azimuth Angle is smaller, after fracture matrix permeability ratio is more than 10, the well drainage and Angle is small, the gap between and, in fact, in view of the low permeability reservoir, fracture matrix permeability ratio generally larger, and considering the could further open and the mine cracks after water injection development direction is difficult to accurately determine the situation, can according to the fracture direction well spacing.

Other relevant research results at home and abroad also confirmed that the well pattern system and fracture azimuth of different configuration relations had a greater influence on the sweep efficiency of reservoir area, the area of three common pattern in different plane $\mathrm{Kx} / \mathrm{Ky}$ permeability ratio and well drainage and the area of the crack in a different direction Angle case calculation analysis has been done for the conformance (table 2-3).

Tab 2-3 Different well pattern well array form, and the permeability ratio statistics area of conformance

\begin{tabular}{|c|c|c|c|c|c|c|c|}
\hline $\begin{array}{c}\text { Crack and well } \\
\text { patten angle }\left({ }^{\circ}\right)\end{array}$ & $\mathbf{k}_{\text {affusion }} / \mathrm{k}_{\mathrm{y}}$ & 1.5 & 2 & 3 & 4 & 5 & 6 \\
\hline \multirow{3}{*}{$\mathrm{A}=0^{\circ}$} & Five method & 0.79 & 0.72 & 0.629 & 0.57 & 0.53 & 0.499 \\
\hline & Seven method & 0.711 & 0.646 & 0.564 & 0.513 & 0.476 & 0.448 \\
\hline & Reverse nine method & 0.508 & 0.462 & 0.404 & 0.367 & 0.34 & 0.32 \\
\hline \multirow{3}{*}{$\mathrm{A}=22.5^{\circ}$} & Five method & 0.66 & 0.603 & 0.526 & 0.478 & 0.444 & 0.48 \\
\hline & Seven method & 0.65 & 0.59 & 0.516 & 0.469 & 0.385 & 0.409 \\
\hline & Reverse nine method & 0.535 & 0.486 & 0.425 & 0.386 & 0.359 & 0.337 \\
\hline \multirow{3}{*}{$A=45^{\circ}$} & Five method & 0.629 & 0.57 & 0.499 & 0.453 & 0.421 & 0.396 \\
\hline & Seven method & 0.66 & 0.60 & 0.525 & 0.477 & 0.443 & 0.414 \\
\hline & Reverse nine method & 0.64 & 0.582 & 0.508 & 0.461 & 0.428 & 0.404 \\
\hline
\end{tabular}

From table 2-3, for the nine well array well pattern and fracture azimuth Angle $45^{\circ}$, five and seven method pattern Angle $0^{\circ}$, area sweep coefficient is the largest, the highest oil displacement efficiency.

Application potential model to measure the fracture system is in a positive and negative directions different fracture propagation length and the area of sweep efficiency, the relationship between the linear water injection: when the injection line direction and fracture direction vertical, with the increase of fracture length, area of sweep efficiency decreases. When injection line direction and fracture direction is parallel, the longer the fracture extension, the higher the sweep efficiency.

Comprehensive the above analysis, for the fractured reservoir, to make the pattern system area sweep coefficient, the greater the displacement efficiency is higher, the well array requirements should be parallel to the direction of crack.Fu Yang, therefore, high platform oilfield reservoir well drainage direction direction of fracture system, namely the east-west.

\section{Economic limit well pattern density}

According to the geological characteristics of low permeable oil fields, generally speaking, the smaller the spacing well spacing density is larger, the better the development effect, the higher the ultimate oil recovery.But the effect of oilfield development should not only consider good or bad, want to consider the pros and cons of economic benefits.Well spacing density is too large, the investment is too high, lead to economic benefits, appear even negative economic benefits. So when choosing, determine the well spacing density necessary to analyze it.

Using the following formula for the evaluation period economic limit production and economic limit well spacing density, economic limit well spacing) to calculate. 


$$
\begin{aligned}
& q_{\min }= \frac{\left(I_{D}+I_{B}\right)(1+R)^{T / 2} \times \beta}{0.0365 \times \tau_{o} \times d_{o} \times T \times\left(P_{o}-O\right)\left(1-D_{c}\right)^{T / 2}} \\
& f_{\min }=\frac{d_{o} \times\left(P_{o}-O\right) \times N \times E_{R}}{\left(I_{D}+I_{B}\right)(1+R)^{T / 2} \times A_{o}} \\
& L=\sqrt{\frac{1}{f_{\min }}}
\end{aligned}
$$

Fu Yang high counter oilfield reservoir economic limit calculation result table

\begin{tabular}{|c|c|c|c|}
\hline $\begin{array}{c}\text { Oil price } \\
(\$ / \mathrm{bbl})\end{array}$ & $\begin{array}{c}\text { economic limit Limit quantity } \\
(\mathrm{t} / \mathrm{d})\end{array}$ & $\begin{array}{c}\text { economic limit well patten density } \\
(\mathrm{a} / \mathrm{km} 2)\end{array}$ & $\begin{array}{c}\text { Economic limit well spacing } \\
(\mathrm{m})\end{array}$ \\
\hline 40 & 2.90 & 36 & 166 \\
\hline 50 & 2.18 & 48 & 144 \\
\hline 60 & 1.79 & 58 & 131 \\
\hline 80 & 1.28 & 81 & 98 \\
\hline 100 & 0.99 & 105 & 111 \\
\hline
\end{tabular}

According to fu Yang high counter oilfield reservoir blocks of various parameters, the calculation results for: oil prices of $\$ 40$ / BBL respectively, 50 \$/ BBL, 60 \$ BBL, 80 \$/ BBL, 100 \$/ BBL, the economic limit well pattern density of 36 respectively $/ \mathrm{km} 2,48 / \mathrm{km} 2,58 / \mathrm{km} 2,81 / \mathrm{km} 2,105$ / $\mathrm{km} 2$.

\section{4.well spacing and row spacing}

\subsection{Row spacing}

$\mathrm{Fu}$ Yang oil layer due to the low permeability reservoir, the wound by row spacing is too big, can't afford to build effective drive system, water injection development characterized by low single-well production, decreasing amplitude is large, to improve the development effect, must first solve the problem of effective drive system.

Start-up pressure gradient in low permeability oilfield is one of the application of reasonable well pattern deployment time to calculate well spacing, use the type test algorithm can find out a given injection-production pressure difference and under the condition of reservoir permeability limit injection-production well spacing (for low permeability fractured reservoir as row spacing) :

$$
\frac{P_{H}-P_{W}}{\ln \frac{R}{r_{W}}} \cdot \frac{2}{R}=\lambda
$$

\subsection{Well spacing}

According to the seismic prediction of sand body, fu Yang high counter oilfield reservoir distributary channel sand body lateral growth on a smaller scale, distributary channel sand body width is only $200 \sim 300 \mathrm{~m}$, in order to make pattern can effectively control the sand body, largest spacing should be controlled within $300 \mathrm{~m}$.

\section{5.well spacing optimization}

$\mathrm{Fu}$ Yang to determine high counter oilfield reservoir reasonable well pattern, row spacing design should not be more than $100 \mathrm{~m}$, at the same time, considering the economic well spacing density and the reservoir sand body width, design of spacing of $300 \sim 400 \mathrm{~m}$, row from $100 \mathrm{~m}$ to $80 \mathrm{~m}$ of six sets of rectangular well pattern, according to the results of numerical simulation concept model, calculating recovery efficiency of different rectangular well pattern, the results showed that $300 \mathrm{x}$ $90 \mathrm{~m}$ pattern recovery is the largest. 


\section{6 .Conclusion}

6.1Fu Yang high counter oilfield reservoir well drainage direction direction of fracture system, namely the east-west.

6.2 Fu Yang high counter oilfield reservoir reasonable well spacing of $300 \mathrm{~m}$, row distance of 90 m.

6.3 Fu Yang high counter oilfield reservoir reasonable well pattern way for large-scale fracturing of rectangular well pattern.

\section{Bibliography}

Yu Guan(1978), female, born in Jan 1978. Hold a Bachelor's degree in petroleum engineering programs from Northeast Petroleum University in 2002. A studying worker of reservoir engineer. Address: No.5 Production Plant Of Daqing Oil Field in Daqing, Heilongjiang City, Heilongjiang City Tel: 0459-4596690;Emai: gyu@petrochina.com.cn

\section{Reference}

[1]Zai Yun Fang et al, study on infiltrative mechanics. Petroindusty publishing.1994:16.23

[2]Li Dao Pin et al, Study on the establish and estimate of infusing and produce in low permeability reservoirs. Petroindusty publishing IN Bei Jing.1997.232-242.

[3]Liu Ding Zeng et al,Study on excessive layers oilfield production.. Petr industy publishing in Bei Jing.1986 